\title{
Robust Adaptive Feedback VBW Model for HM-Based SM Controller for DC-DC Multicellular Converters
}

\author{
R. Hamdi, A. H. Hamida, and O. Bennis
}

\begin{abstract}
This manuscript describes a comparative analysis between the variable-bandwidth (VBW) of the hysteresis modulation (HM) and the unipolar pulse-width modulation (PWM) by double intersection, both based on the conventional sliding mode (CSM) strategy. The two adopted techniques are applied to a new topology of a bidirectional asynchronous multichannel DC-DC Buck converter. The cells are parallelconnected and operating in continuous conduction mode (CCM). Our study contributes to the control method and the implementation, the command is applied at the same time without phase shift to an identical three cells of a non-isolated and asynchronous converter, this topology is rarely studied. The aim is to fix the switching frequency of the converter while referring to an adaptive feedback approach. Therefore, we integrate a hysteresis modulator and develop a variable hysteresis band function to attenuate the non-linearity phenomenon of the conventional sliding mode. Then, we apply an adaptive feedback current control technique to surpass the dilemma of the variable switching frequency for high power converters. The results demonstrate that the studied system became more stable, more efficient, and able to cope with variations in input voltage, load, and desired output voltage. The same results clearly show the areas where significant differences have been found between the two strategies. Simulation studies in the MATLAB ${ }^{\circledR}$ / Simulink ${ }^{\mathrm{TM}}$ environment are performed to analyze system performance and assess its robustness and stability under parametric variation.
\end{abstract}

Index Terms-Adaptive control technique, high power converters, hysteresis modulator, multicellular DC-DC converters, paralleled-converters, pulse width modulator, sliding mode controller.

\section{INTRODUCTION}

Power electronic converters have a significant role in several areas including energy storage, automation, transport, high power industrial drives, and transmission/distribution of electrical energy [1], [2]. DC-DC multicellular converters, with many different topologies, represent a hotspot in modern technology and have revolutionized switching frequencies. Operating the converters at high switching frequencies allows to reduce the size of reactive components (inductors and capacitors) and it contributes to the improvement of the output voltage's quality of the converter.

Recently, some researchers have been concerned with stringent control features and higher efficiency of multicellular [3] - [9]. The methods of controller design are classified into two categories: linear and nonlinear. The linear methods, such as the PI controller which is a main linear controller [10], are performed relying on locally linearized models. Hence, their performance will not remain the same under any changes on equilibrium points. The dynamic equations of the power electronic converters have a nonlinear nature due to the multiplications of the state variables by the control inputs [11]. Therefore, nonlinear methods such as the sliding mode have been widely studied and recommended for the control of converters. Nonlinear Sliding mode controllers applied to parallel multi-cell converters combine control concepts with multiple sliding surfaces and integral variable structure.

The controllers developed for paralleled multiphase converters take into consideration most of the characteristics mentioned above [12]. They are easy to design, robust, and have good transient and stable performance, yet, it suffers from the problem of high-frequency oscillation (chattering) due to the practical limitations of system components and the problem of switching frequency variation. To date, several researchers have proposed numerous methods to constrict the switching frequency of SM controllers [13] - [17]. In particular, those employing the pulse-width modulation (PWM) where the state-space averaging technique is incorporated into the controller's modeling. Alternatively, the variation of the switching frequency of SM controllers can be limited by changing the modulation method of the SM controllers from PWM to hysteresis modulation (HM). The HM for implementing the control law normally requires either constant timer circuits to be incorporated to ensure constant switching frequency operation [18], [19]. Furthermore, they fix the switching frequency, mitigate the undesired transient response and achieve a good compromise between transient and stationary performance. All these promising results have been experimentally proven on a closed-loop system. Previous studies have proposed using the extended linearization method for the design of the sliding mode controller, and then improving robustness using the combined controllers. Thus, they developed a procedure to choose the high-pass filter parameters of the sliding mode-controlled converters. In addition, they presented derivatives of sliding mode control, including the direct /indirect sliding mode, the integral sliding mode, the proportional sliding mode, and the high order sliding mode [20] - [23]. As far, sliding mode control has been widely studied and has proven to be a future solution for generations of power converters, yet, it suffers from the problem of high-frequency oscillation (chattering) due to the practical limitations of system components and the problem of
R. Hamdi and A. H. Hamida are with the LMSE Laboratory, Electrical Engineering Department, Biskra University, 07000 Biskra, Algeria (corresponding author to provide e-mail: rihab.hamdi2012@gmail.com).

O. Bennis is with the PRISME Institute, University of Orléans, 21 rue Loigny La Bataille, 28000 Chartres Orléans, France. 
switching frequency variation by applying the traditional sliding mode.

This leads us to propose an implementation of the sliding mode controller by hysteresis modulator and using an adaptive hysteresis band that varies with parameter changes. The implementation is easy to employ and does not require additional auxiliary circuits or complex calculations. The introduction of a hysteresis band as the limit conditions of the sliding mode, delays the period of states exchange and gives a sign to control the switching frequency of the system, and therefore, the trajectory of the system variates close to the excesses of the band. So, the practical problem of chattering will be solved. Particularly, boundary layer-based control schemes allow multicell converters to operate with a fixed switching frequency [24].

We will illustrate this procedure by designing an adaptive feedback control technique of a buck converter based on sliding-mode and discuss the results in comparison with a PWM approach.

The remainder of the paper is organized as demonstrated: In Section II, the adopted system is described and modeled. Section III reviews the control mechanism based on the sliding mode controller. Section IV is devoted to analyzing the simulation results and discussing the effectiveness of the control strategies. The conclusion is reported in Section V.

\section{Paralleled Bidirectional Multi-Cell ConVerters}

The studied system is a DC-DC Buck converter, bidirectional, asynchronous, non-isolated, non-linear, and three-cellular where his switching commutations are associated in parallel. Fig. 1 shows the adopted system topology. It consists of a constant DC input voltage source $V_{\text {in }}$ connected to three similar modules sharing a resistive load $\mathrm{R}$ and a filter capacitor $\mathrm{C}$. Each module is based on an implemented controllable power MOSFETs $S$, the antiparallel diode $\mathrm{D}$ that authorizes the embedded switch to exhibit a bidirectional current conduction property and a filter inductor L. Note that the parallel switching Buck converter operates in continuous conduction mode (CCM). The three cells are identical, in other words, $\mathrm{L}_{1}=\mathrm{L}_{2}=\mathrm{L}_{3}$.

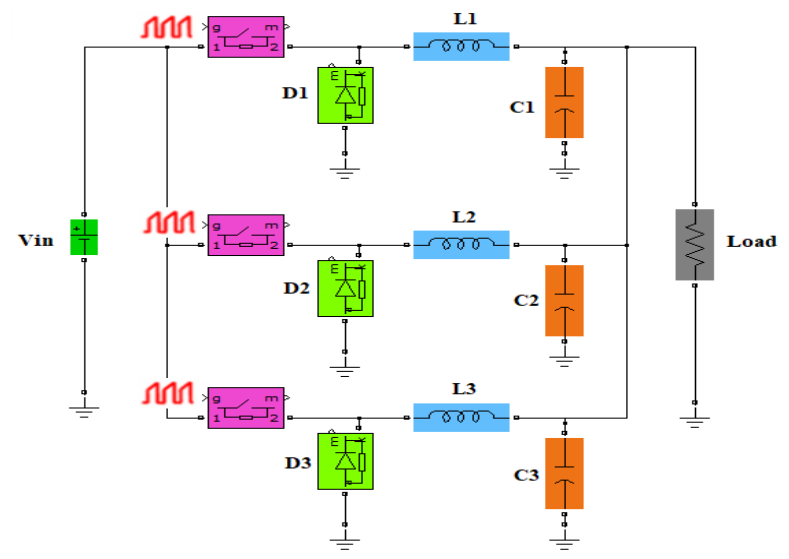

Figure 1. Three-channel Buck converter parallel-associated.

The converter can be represented by a system of equations based on a model with mean values, then the system dynamics of the studied converter can be expressed as:

$$
\begin{gathered}
L \frac{d I_{L j}}{d t}=\beta V_{\text {in }}-V_{\text {out }} \\
C \frac{d v_{\text {out }}}{d t}=I_{L}+\frac{V_{\text {out }}}{R}
\end{gathered}
$$

Where $I_{L j}$ is the current flowing through inductance $\mathrm{j}=$ $1,2,3, \mathrm{I}_{\mathrm{L}}$ is the current at the output of the converter, $\mathrm{V}_{\text {in }}$ is the input voltage and $\mathrm{V}_{\text {out }}$ is the output voltage of our converter, $\mathrm{V}_{\text {ref }}$ is the desired output voltage and $\beta$ is the duty cycle. The state of space can be expressed as:

$$
\begin{gathered}
x_{1}=V_{\text {ref }}-V_{\text {out }} \\
x_{2}=\dot{x}_{1}=-\frac{d V_{\text {out }}}{d t}=\frac{1}{C}\left(-\frac{V_{\text {out }}}{R}-\int \frac{u V_{\text {in }}-V_{\text {out }}}{L} d t\right)
\end{gathered}
$$

This model can be used directly to simulate the converter because the three cells are identical, in MATLAB® / Simulink ${ }^{\mathrm{TM}}$ type environment.

\section{StUdy OF THE PROPOSED STRATEGY}

We propose an adaptive feedback current control technique based on the sliding mode approach as shown in Fig. 2 , developed in the continuous domain, to stabilize parallel multi-phase standalone converter. We developed a variableband width (VBW) function, illustrated in Fig. 3, for the hysteresis modulation (HM) that automatically compensates for the parametric variations of the converter and the variation of the line impedance, such that it allows the three-channel paralleled DC-DC converter to share the load and does not require the modules to be interconnected. On the other hand, we illustrate a unipolar pulse width modulation (PWM) by double intersection control technique, clarified in Fig. 4, Fig. 5, Fig. 6, and Fig. 7, without adaptive feedback to validate our adopted strategy; however, this approach has accentuated the problem of variable switching frequencies that requires a highbandwidth current sensor. At this point in our work, we are interested in an adaptive feedback current control (CC) solution to overcome this problem and adapt a variablebandwidth of the hysteresis modulation to mitigate the nonlinearity phenomenon in conventional sliding mode control to fix the switching frequency.

For the mathematical model of the system in question, operating in CCM, describing the states of space necessary for the design of the sliding mode control (SMC), the reformed expression of the state of space is:

$$
\left[\begin{array}{l}
\dot{x}_{1} \\
\dot{x}_{2}
\end{array}\right]=\left[\begin{array}{cc}
0 & 1 \\
-\frac{1}{L C} & -\frac{1}{R C}
\end{array}\right]\left[\begin{array}{l}
x_{1} \\
x_{2}
\end{array}\right]+\left[\begin{array}{c}
0 \\
-\frac{V_{i n}}{L C}
\end{array}\right] u+\left[\begin{array}{c}
0 \\
\frac{V_{r e f}}{L C}
\end{array}\right]
$$

Employing the sliding mode control (SMC) and taking into account the state trajectory that includes the control parameters $\mathrm{x}_{1}$ and $\mathrm{x}_{2}$, we can determine the switching function $\mathrm{u}$. We will apply the same control function to each cell simultaneously.

$$
\begin{gathered}
S=\alpha x_{1}+x_{2}=J x \\
\left\{\begin{array}{c}
J=[\alpha, 1] \\
x=\left[x_{1}, x_{2}\right]^{T}
\end{array}\right.
\end{gathered}
$$


That forms the control law:

$$
u=\left\{\begin{array}{cc}
1={ }^{\prime} O N^{\prime} & \text { When } S>k \\
0==^{\prime} O F F^{\prime} & \text { When } S<k
\end{array}\right.
$$

The convergence conditions are the criteria that allow the dynamic errors of the system to converge towards the sliding surface. They are ensured by a judicious choice of the function of LYAPUNOV, which guarantees the attraction of variables to regulate to their references, to build the discontinuous control size, and meet the stability criterion:

$$
\lim _{S \rightarrow 0} S . \dot{S}<0
$$

Thus, the existing condition for the adopted control strategy is:

$$
\dot{S}= \begin{cases}J \dot{x}<0 & \text { for } 0<S<\xi \\ J \dot{x}>0 & \text { for }-\xi<S<0\end{cases}
$$

where $\xi$ is a positive quantity, infinitely small and arbitrarily chosen.

Substituting (3) and (5), we find:

$$
S=\frac{1}{R}\left(V_{\text {ref }}-V_{\text {out }}\right)-i_{C}
$$

The sliding coefficient is set as (11) and thus the above equation is valid:

$$
\alpha=\frac{1}{R C}
$$

We can therefore deduce the conditions of existence:

$$
\begin{gathered}
\lambda_{1}=\left(\alpha C-\frac{1}{R}\right) x_{2}-\frac{1}{L} x_{1}+\frac{V_{r e f}-V_{i n}}{L} \prec 0 \\
\lambda_{2}=\left(\alpha C-\frac{1}{R}\right) x_{2}-\frac{1}{L} x_{1}+\frac{V_{r e f}}{L} \succ 0
\end{gathered}
$$

Hence, we focus on the adaptive feedback current control technique in continuous conduction mode (CCM). So that, the expression of the current variation $\Delta \mathrm{I}_{\mathrm{L}}$, as a function of the input voltage $\mathrm{V}_{\text {in }}$, the output voltage $\mathrm{V}_{\text {out }}$, the switching frequency $f_{w}$, and the value of the inductance $\mathrm{L}$, can be shown as:

$$
\Delta I_{L}=\frac{\left(V_{\text {in }}-V_{\text {out }}\right)}{L . f w} \cdot\left(\frac{V_{\text {out }}}{V_{\text {in }}}\right)
$$

Still, to ensure the operation at a fixed frequency of the proposed hysteresis modulator, a requirement is imposed, and that the hysteresis bandwidth must satisfy it, is:

$$
B_{\text {Variable-Width }}=\frac{\Delta I_{L}}{2}=\frac{\left(V_{\text {in }}-V_{\text {out }}\right)}{2 . L . f w} \cdot\left(\frac{V_{\text {out }}}{V_{\text {in }}}\right)
$$

The dynamic performance of the two schemes needs to be demonstrated under conditions when some changes are imposed and a feedforward transient occurs. Simulations are performed for various cases of the circuit parameter variations: load changes, input voltage changes, and reference voltage changes.

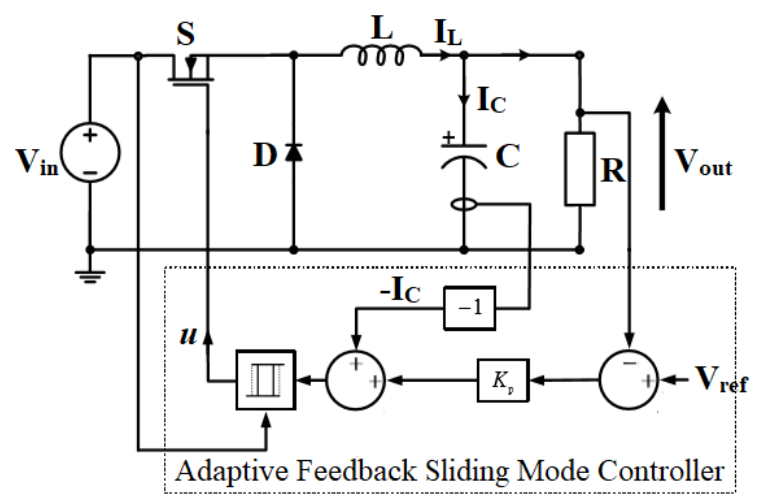

Figure 2. VBW HM-based SM controller scheme.

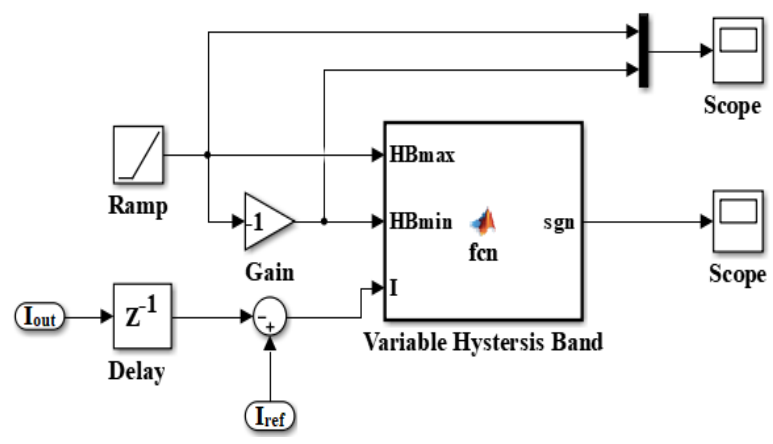

Figure 3. The variable hysteresis band was simulated using MATLAB® tools.

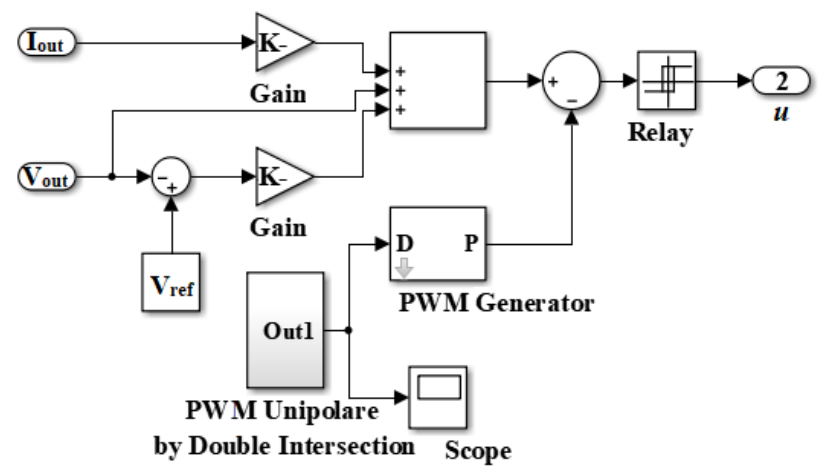

Figure 4. The unipolar PWM by double intersection-based SM controller scheme. 


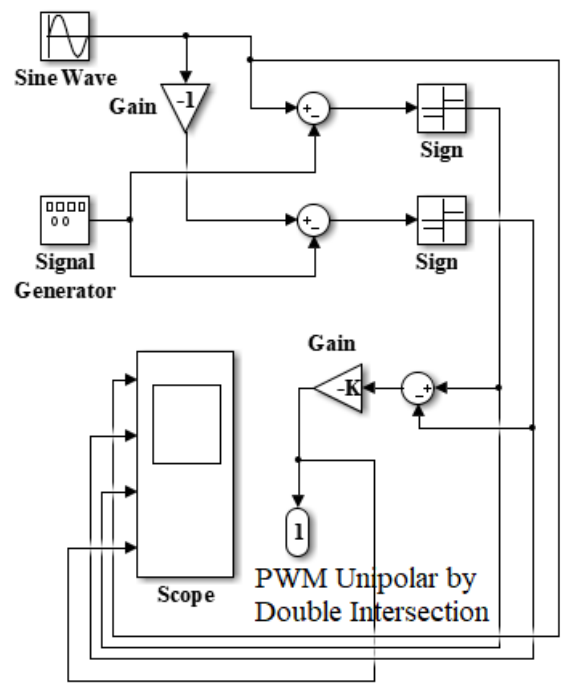

Figure 5. The unipolar PWM by double intersection is simulated using MATLAB® tools.

\section{Simulation Results AND Discussion}

In this part, and to properly study the behavior and performance evaluation of the closed-loop converter and the various control techniques synthesized in the previous section, particularly when modifying the operating conditions, we will simulate the behavior of a three-cell chopper connected to an $\mathrm{R}$ load. A robustness test was carried out to analyze the sensitivity of the strategies and the correctors implemented concerning possible variations in the parameters of the model. For the parameter's identification of the studied converter [25], we determine the nominal values of the inductance $L$ and the capacitance $\mathrm{C}$ using the conditions below:

The current through the inductance must be within a reasonable interval, for all the conditions of charge, because our converter is operating in continuous conduction mode.

$>$ The maximum ripple of the output voltage should not exceed a small percentage, usually $5 \%$ of the output voltage $\mathrm{V}_{\text {out }}$.

Taking these conditions into account, the LC filter must obey the conditions of the relationships below, where $f_{w}$ corresponds to the switching frequency and $\beta$ is the duty cycle.

$$
\begin{gathered}
L \geq \frac{V_{\text {in }}}{\Delta I_{\text {out } \max } \cdot f_{w}} \beta(1-\beta) \\
C \geq \frac{(1-\beta)}{8 L \cdot f_{w}^{2}}\left(\frac{V_{\text {out }}}{\Delta V_{\text {out }}}\right)
\end{gathered}
$$

Table I shows the specifications that we adopted of the studied buck converter simulated in the MATLAB ${ }^{\circledR}$ environment.
TABLE I. SPECIFICATIONS OF THE PARALLELED THREE-CHANNEL

\begin{tabular}{|c|c|c|}
\hline \multirow{2}{*}{ Parameters } & \multicolumn{2}{|c|}{ Characteristics } \\
\hline & Description & Nominal value \\
\hline Input voltage & $\mathrm{V}_{\text {in }}$ & $24 \mathrm{~V}$ \\
\hline Capacitance & $\mathrm{C}$ & $60 \mu \mathrm{F}$ \\
\hline Inductance & $\mathrm{L}$ & $50 \mathrm{mH}$ \\
\hline Resistance & $\mathrm{R}$ & $12 \Omega$ \\
\hline Switching frequency & $f_{w}$ & $400 \mathrm{kHz}$ \\
\hline Desired output voltage & $\mathrm{V}_{\text {ref }}$ & $12 \mathrm{~V}$ \\
\hline
\end{tabular}
BUCK CONVERTER

Fig. 8 duplicates the output voltage response for the unipolar PWM by double intersection-based SMC. This control technique generates a scrambled and poor-quality signal and represents more variation in amplitude of the oscillations, with an overshoot despite having acceptable accuracy and reference line tracking. This result highlights the major contribution of our work, thanks to the developed strategy, we achieve a significant reduction in the variation of the switching frequency. Fig. 9 shows the output voltage response for the VBW HM-based SMC, it seems clear that the system achieves the best compromise passing from the transient regime to the stationary regime. Thus, its transition response is smoother, more stable, without overshoot, and with less chatter. It appears clearly from Fig. 10 and Fig. 11, during an increase/decrease in resistance every $0.2 \mathrm{~s}$, that the closedloop output voltage response reacting with the unipolar PWM by double intersection-based SMC exhibit an undesired transient drop that lasts a few seconds and disturbs the smoothness of the output voltage followed abruptly by a steady-state. While, in the other case, the system compensates for a transient drop in a soft way. Through the output current simulation results, we can reveal that the VBW HM-based SM goes perfectly with the load changes to even almost assure that there is no transient regime. Fig. 12 and Fig. 13 point out the output voltage response and the output load current response for the two controllers when the system undergoes a change in the input supply at $0.2 \mathrm{~s}$ (Vin varied from $24 \mathrm{~V}$ to $50 \mathrm{~V}$ ). For the two cases, after $0.2 \mathrm{~s}$, the chattering increase. However, the output voltage and the output load current vary around the reference values. The zoom-in clearly shows an increase in the amplitude of the oscillations accompanied by an upward shift of the output voltage, in a steady-state regime, when the input voltage increases, it comes down to the variation of the switching frequency. Fig. 14 and Fig. 15 present the output voltage response for the two controllers when the system undergoes a change in the output reference $\left(\mathrm{V}_{\text {ref }}\right.$ varied from $12 \mathrm{~V}$ to $20 \mathrm{~V})$.

The carried-out simulations show extremely encouraging outcomes as far as reference tracking effectiveness and robustness, a quick estimation of the control law permits a quicker dismissal of the unsure load impact. They demonstrate the propriety of sliding mode control for such sort of framework. These results highlight the major contribution of our work, thanks to the developed strategy, we achieved a significant reduction in the variation. 
The results in terms of stability assessment and performance analysis under system parameters variation are recapitulated in Table II, Table III, and Table IV.

TABLE II. C COMPARATIVE PERFORMANCES WHEN LOAD CHANGES

\begin{tabular}{|l|l|l|}
\hline \multirow{2}{*}{\multicolumn{1}{|c|}{ Specifications }} & \multicolumn{2}{c|}{ Load Variation } \\
\cline { 2 - 3 } & $\begin{array}{c}\text { Unipolar PWM- } \\
\text { based SMC }\end{array}$ & $\begin{array}{c}\text { VBW HM- } \\
\text { based SMC }\end{array}$ \\
\hline Time of compensation & $0.02 \mathrm{~s}$ & $0.015 \mathrm{~s}$ \\
\hline The drop width & $0.38 \mathrm{~V}$ & $0.13 \mathrm{~V}$ \\
\hline Amplitude of oscillations & $\pm 0.15 \mathrm{~V}$ & $\pm 0.1 \mathrm{~V}$ \\
\hline Response time & $0.02 \mathrm{~s}$ & $0.03 \mathrm{~s}$ \\
\hline
\end{tabular}

TABLE III. COMPARATIVE PERFORMANCES WHEN THE INPUT VOLTAGE CHANGES

\begin{tabular}{|l|l|l|}
\hline \multirow{2}{*}{ Specifications } & \multicolumn{2}{|c|}{ Input Voltage Variation } \\
\cline { 2 - 3 } & \multicolumn{2}{|c|}{ Amplitude of oscillations } \\
\hline For $\mathrm{t}<0.2 \mathrm{~s}$ & $\pm 0.05 \mathrm{~V}$ & $\pm 0.12 \mathrm{~V}$ \\
\hline For $\mathrm{t}>0.2 \mathrm{~s}$ & $+0.3 \mathrm{~V}$ & $\pm 0.12 \mathrm{~V}$ \\
\hline
\end{tabular}

TABLE IV. COMPARATIVE PERFORMANCES WHEN THE REFERENCE VOLTAGE CHANGES

\begin{tabular}{|l|l|c|}
\hline \multirow{2}{*}{\multicolumn{1}{|c|}{ Specifications }} & \multicolumn{2}{|c|}{ Reference Voltage Variation } \\
\cline { 2 - 3 } & $\begin{array}{c}\text { Unipolar PWM- } \\
\text { based } \text { SMC }\end{array}$ & $\begin{array}{c}\text { VBW HM-based } \\
\text { SMC }\end{array}$ \\
\hline Time of transition & $0.02 \mathrm{~s}$ & $0.03 \mathrm{~s}$ \\
\hline Amplitude of oscillations & $\pm 0.08 \mathrm{~V}$ & $\pm 0.12 \mathrm{~V}$ \\
\hline
\end{tabular}
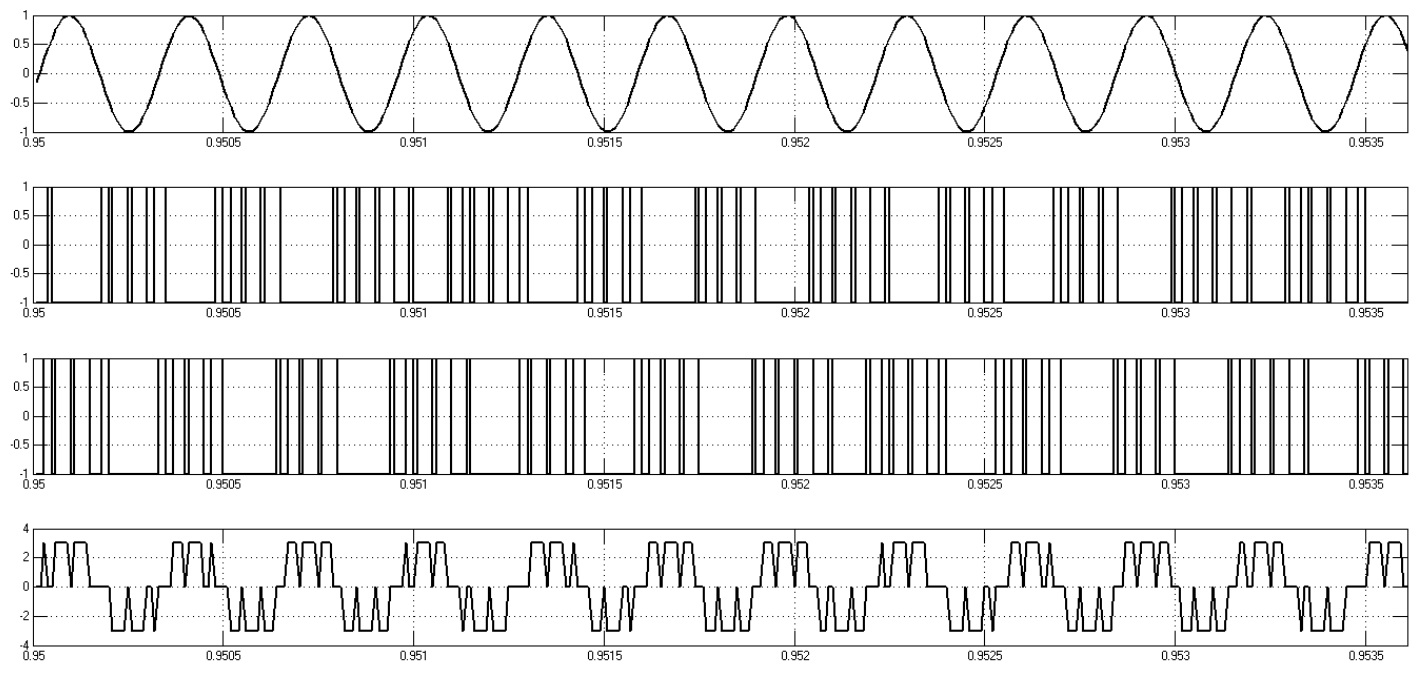

Figure 6. The construction of the unipolar PWM by double intersection from a sine wave and a bipolar pulse.
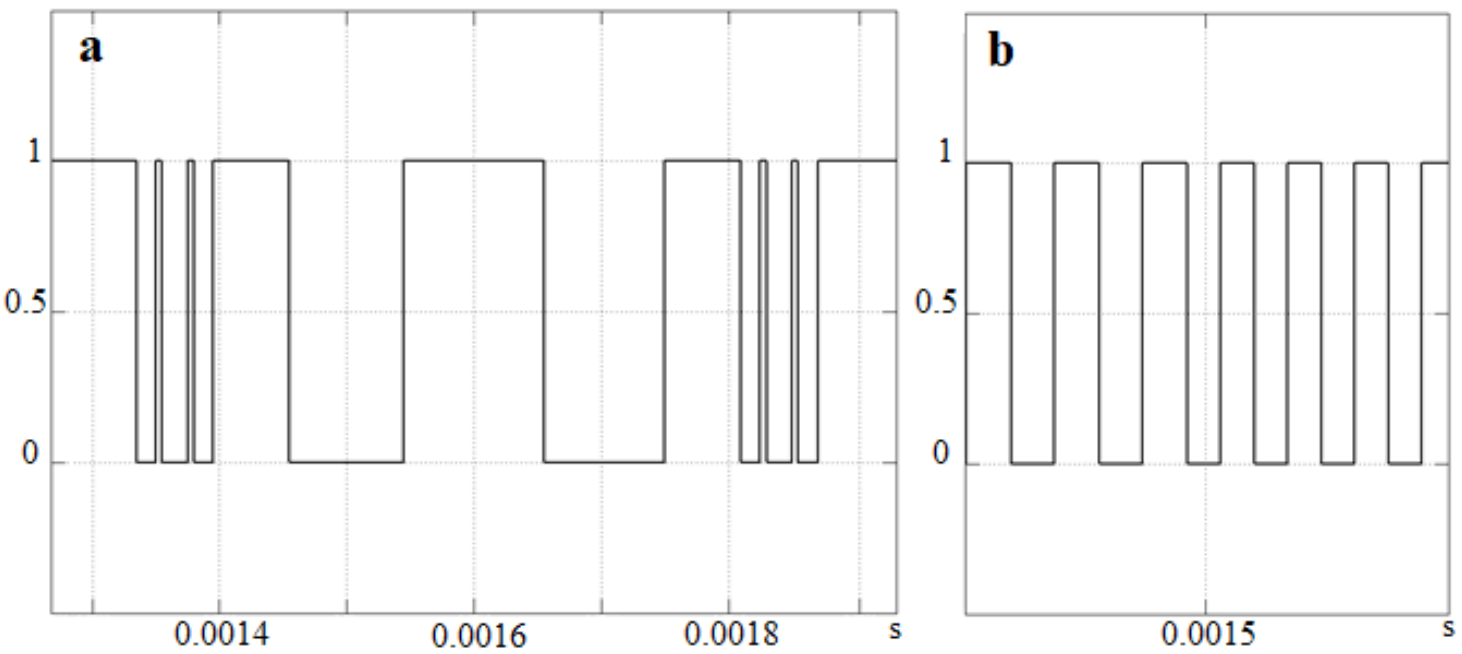

Figure 7. The switching control signal. (a) For the unipolar PWM by double intersection-based SMC. (b) For the VBW HM-based SMC. 


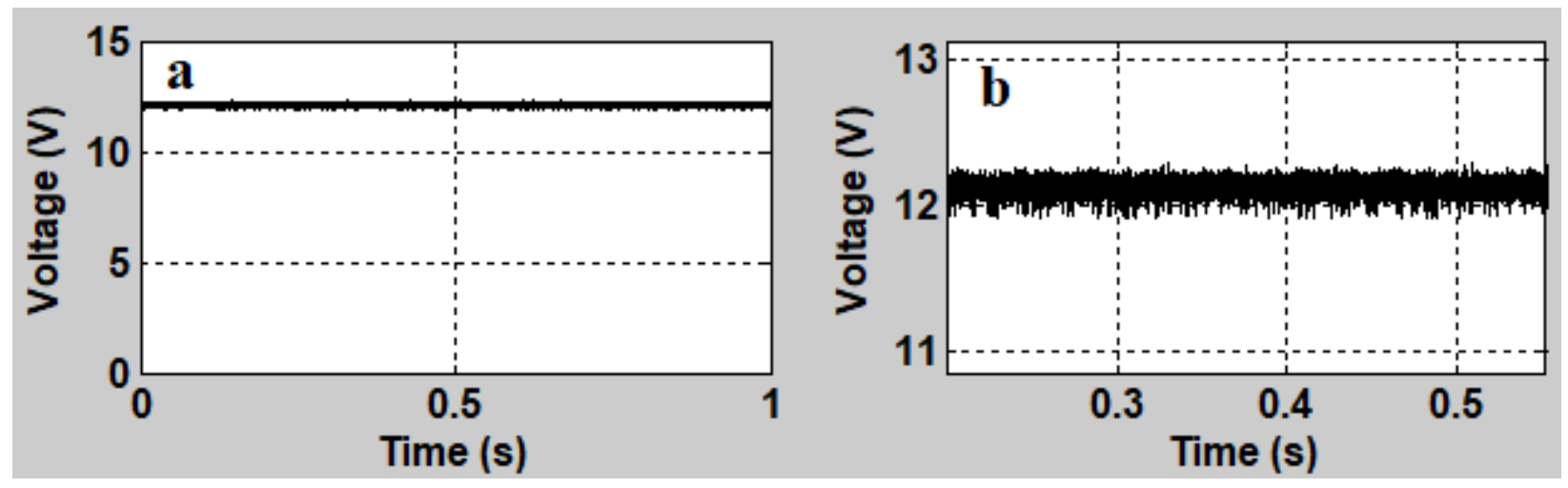

Figure 8. (a) The Output voltage response for the unipolar PWM by double intersection-based SMC. (b) Zoom in.
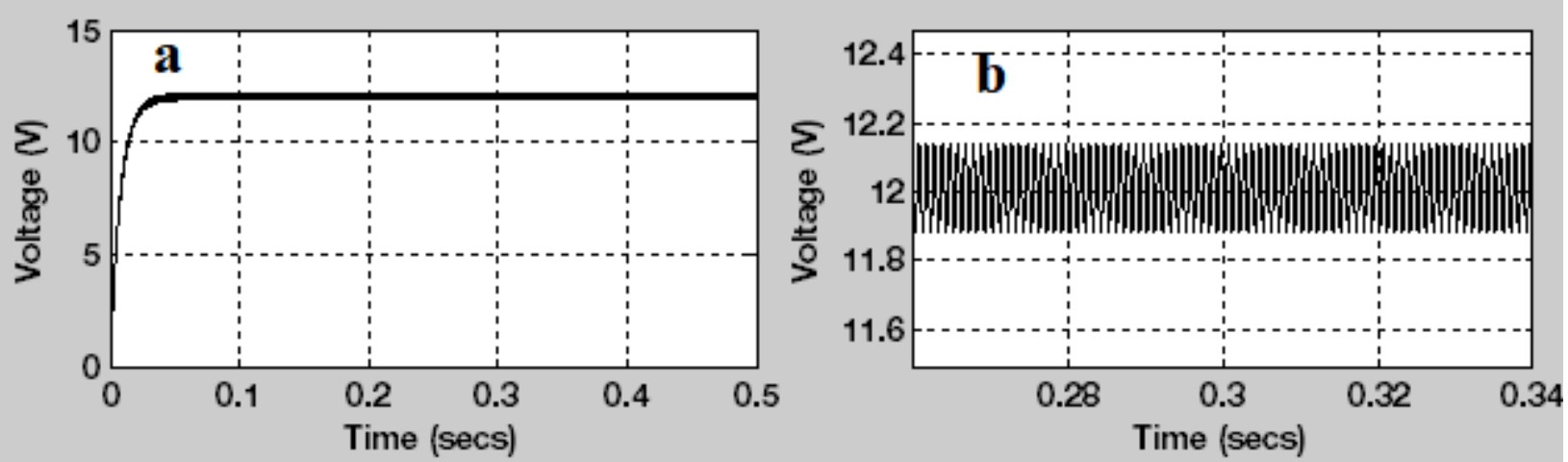

Figure 9. (a) The Output voltage response for the VBW HM-based SMC. (b) Zoom in.
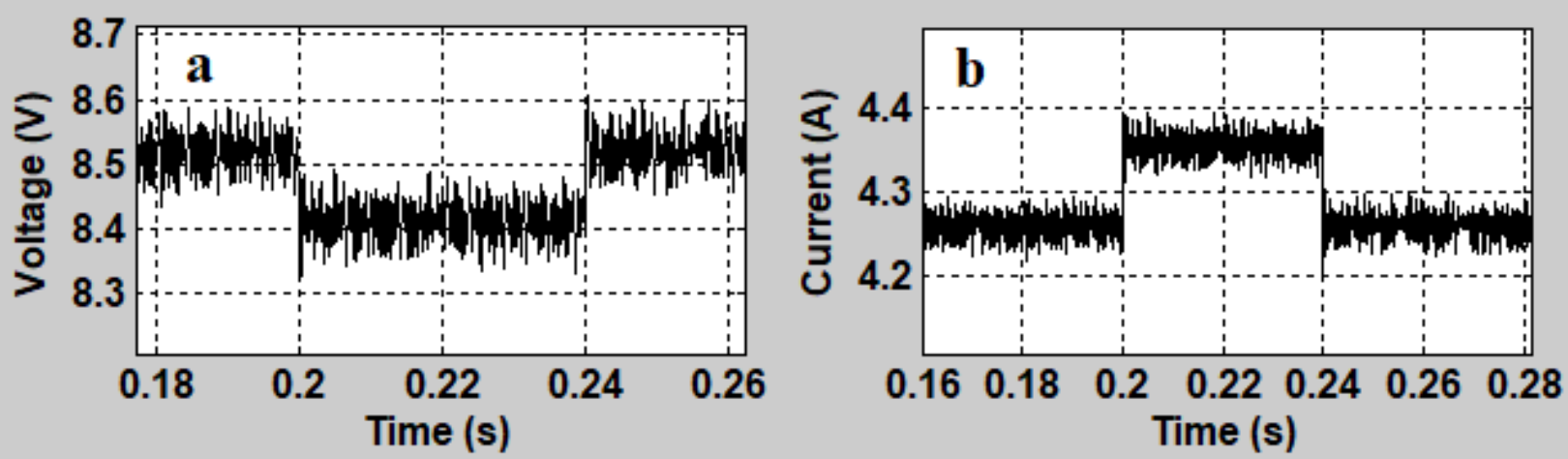

Figure 10. (a) The output voltage response. (b) The output load current response.

Both for the unipolar PWM by double intersection-based SMC when the system undergoes a slight change in the load.
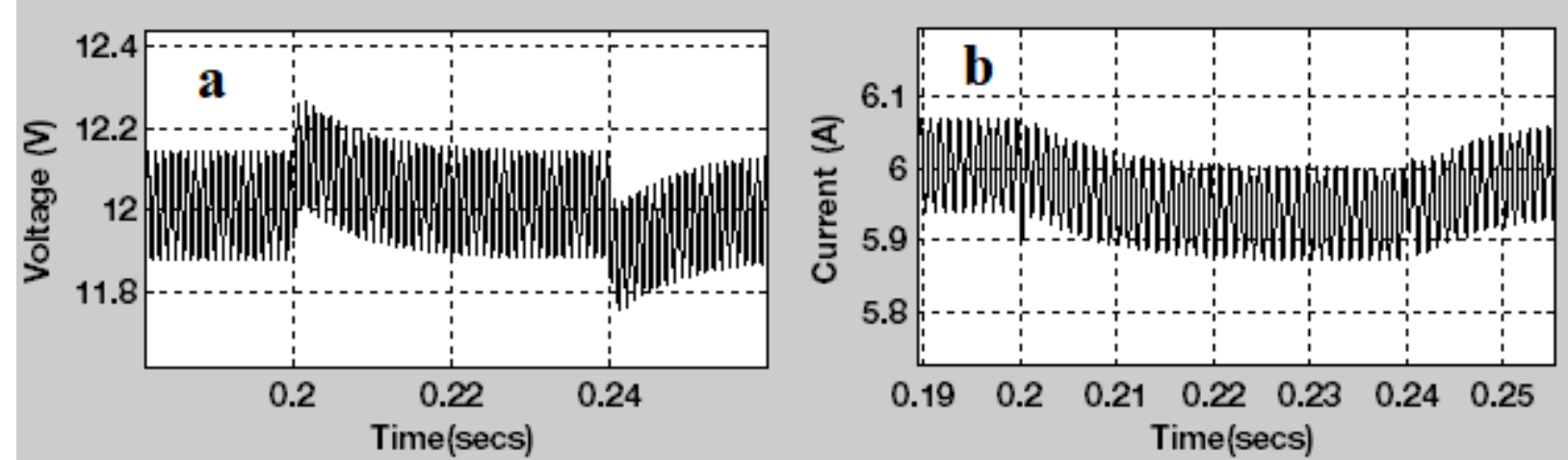

Figure 11. (a) The output voltage response. (b) The output load current response. Both for the VBW HM-based SMC when the system undergoes a slight change in the load resistance. 


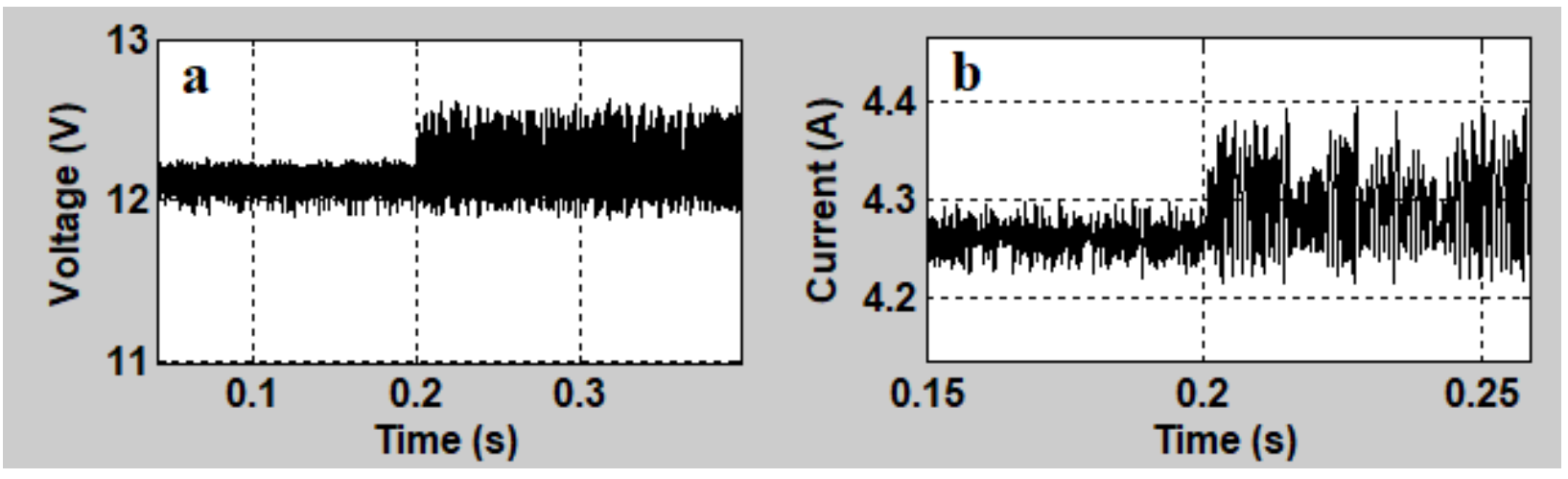

Figure 12. (a) The output voltage response. (b) The output load current response. Both for the unipolar PWM by double intersection-based SMC when the system undergoes a change in the input supply.
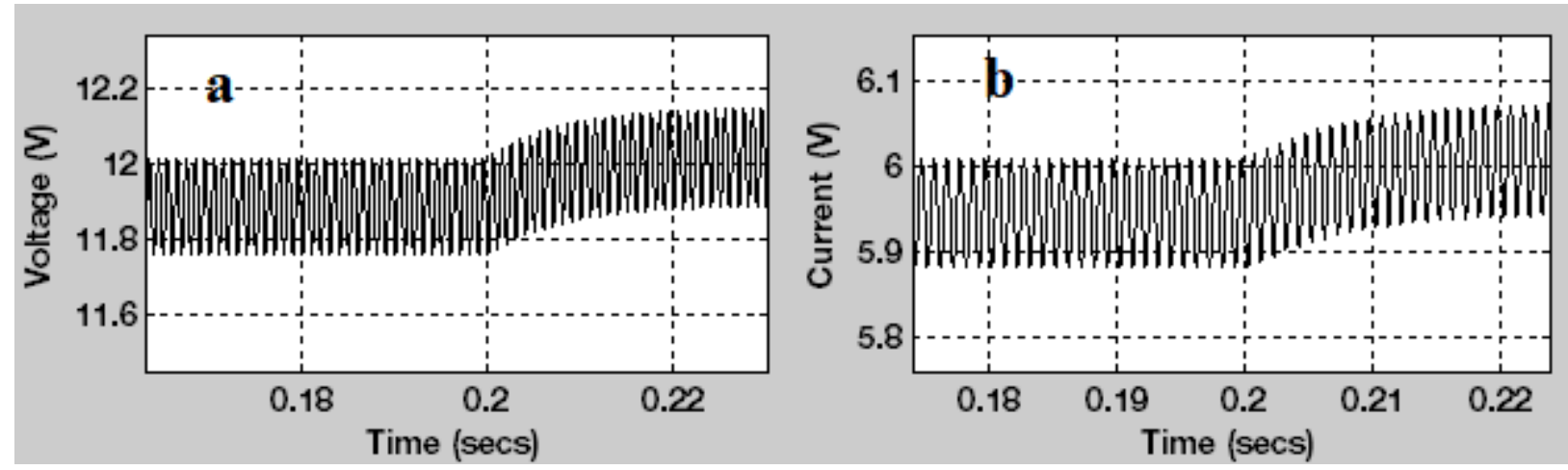

Figure 13. (a) The output voltage response. (b) The output load current response.

Both for the VBW HM-based SMC when the system undergoes a change in the input supply.
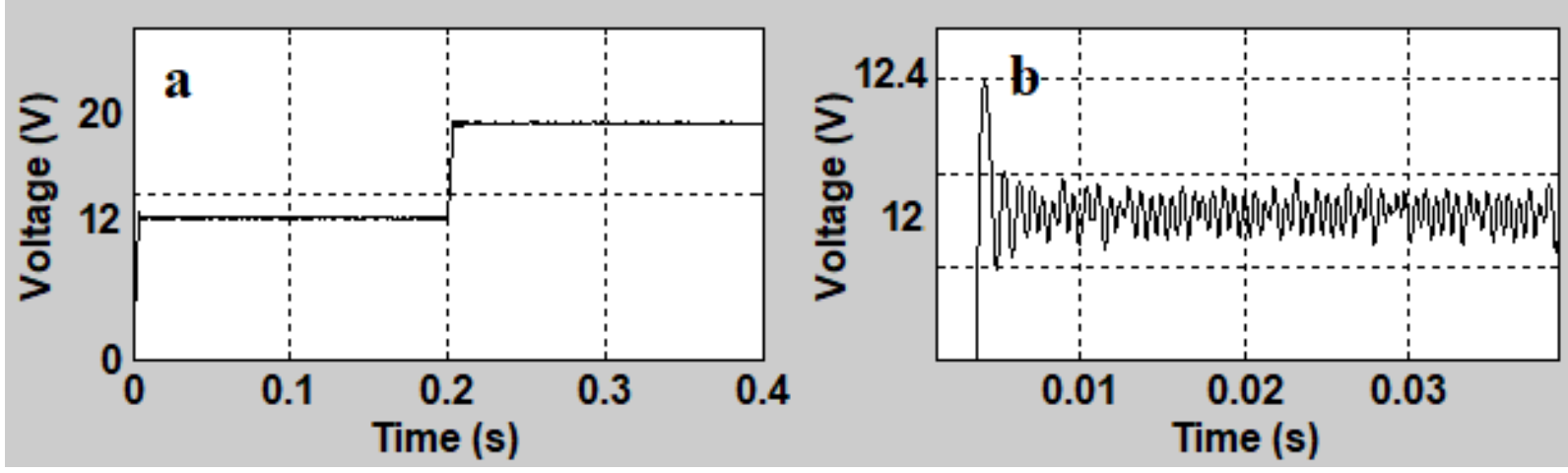

Figure 14. (a) The output voltage response for the unipolar PWM by double intersection-based SMC when the system undergoes a change in the output reference. (b) Zoom in.
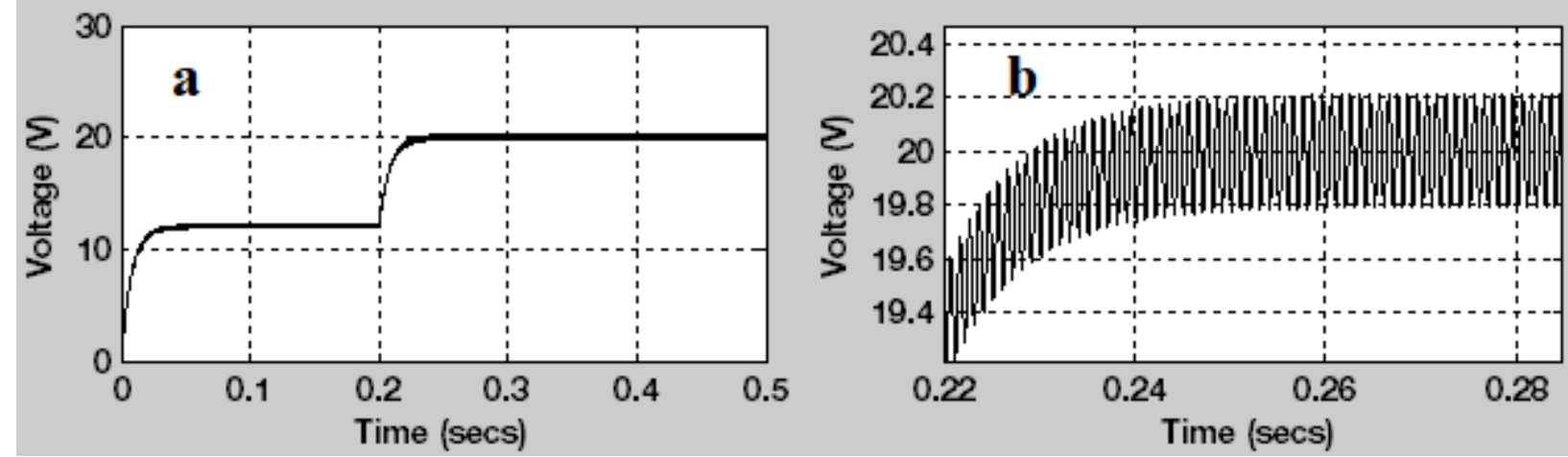

Figure 15. (a) The output voltage response for the VBW HM-based SMC when the system undergoes a change in the output reference. (b) Zoom in. 


\section{CONCLUSION}

The variable-bandwidth hysteresis modulation is favored and has many desirable features: easy-designed because each sliding surface is independently controlled, smooth transient responses tested under parametric variations, eliminates the problem of chattering caused by the switching of the MOSFETs, the impact of high switching frequencies is managed by the integrators and provides high efficiency since it offers a greatly desired output voltage tracking. The VBW HM-based SMC is faster to the point that the response time at 5\% is mostly short. His appropriate dynamic accuracy is characterized by zero overshoot during the transient regime for the output voltage response, contrariwise to the unipolar PWM by double intersection-based SMC that have 3\% overshoot. The output voltage regulation is improved from $0.15 \%$ $\left(\mathrm{V}_{\text {in }}=24 \mathrm{~V}\right)$ to $60 \%\left(\mathrm{~V}_{\text {in }}=24 \mathrm{~V}\right)$ through the VBW HM-based SMC. Add to that, the frequency variation is reduced from $40 \%$ to $15 \%$ with the developed strategy. The various control techniques provide similar performances, they have improved the dynamic conduct and they can adapt to include voltage and load varieties. The use of variable bandwidth hysteresis modulation and fixing of the switching frequency leads to large-scale dynamics.

\section{REFERENCES}

[1] Michele Cucuzzella, Riccardo Lazzari, Sebastian Trip, Simone Rosti, Carlo Sandroni, Antonella Ferrara,"Sliding mode voltage control of boost converters in DC microgrids", Control Engineering Practice, Volume 73, 2018, Pages 161-170.

[2] R. Hamdi, A.H. Hamida, O. Bennis, F. Babaa, "HM-Based SMVC with Adaptive Feedforward Controller Applied to DC-DC Converter," in 2020 International Conference on Electrical and Information Technologies (ICEIT), IEEE: 1-6, 2020.

[3] Q. Zhong, C. Wang, Y., \& Ren, B. (2017). UDE-based robust droop control of inverters in parallel operation. IEEE Transactions on Industrial Electronics, 64(9), 7552-7562.

[4] W. Do, K. Eguchi, A. Shibata, "An analytical approach for parallel switched-capacitor converter," Energy Reports, 6, 338-342, 2020.

[5] M. Srinivasan, A. Kwasinski, "Control analysis of parallel DC-DC converters in a DC microgrid with constant power loads," International Journal of Electrical Power and Energy Systems, 122, 106207, 2020.

[6] H. Li, X. Jiang, Y. Zou, C. Liu, "A time-domain stability analysis method for paralleled LLC resonant converter system based on Floquet theory," Microelectronics Reliability, 114, 113849, 2020.

[7] M.S.B. Ranjana, N. Sreeramulareddy, R.K.P. Kumar, "A novel nonisolated switched inductor floating output DC-DC multilevel boost converter for fuel cell applications," 2014 IEEE Students' Conference on Electrical, Electronics and Computer Science, SCEECS 2014, (March), 2014.

[8] M. Sagar, B. Ranjana, "A novel non-isolated switched inductor floating output DC-DC multilevel boost converter for fuel cell applications A Novel Non-Isolated Switched Inductor Floating Output DC-DC Multilevel Boost Converter For Fuel cell Applications," (March), 2014.

[9] S. Ben Said, K. Ben Saad, M. Benrejeb, "ScienceDirect HIL simulation approach for a multicellular converter controlled by sliding mode," International Journal of Hydrogen Energy, 1-7, 2017.

[10] P. Djondiné, "Overview of Control Techniques for Multicellular Converter 1 Introduction 2 Research Methodology," 10-14, 2018.
[11] P. Taylor, M. Defoort, M. Djemai, T. Floquet, W. Perruquetti, "International Journal of Systems Science Robust finite time observer design for multicellular converters," (April 2013), 37-41.

[12] F. Engelkemeir, A. Gattozzi, G. Hallock, R. Hebner, "Electrical Power and Energy Systems An improved topology for high power softswitched power converters," Electrical Power and Energy Systems, 104(May 2017), 575-582, 2019.

[13] H. Al-Baidhani and al., "Sliding-Mode Voltage Control of Dynamic Power Supply for CCM," IEEE International Symposium on Circuits and Systems (ISCAS), 1-5, 2019.

[14] Y. Wu, Y. Huangfu, R. Ma, A. Ravey, D. Chrenko, “A strong robust DC-DC converter of all-digital high-order sliding mode control for fuel cell power applications," Journal of Power Sources, 413, 222-232, 2019.

[15] S. Das, M. Salim Qureshi, P. Swarnkar, "Design of integral sliding mode control for DC-DC converters," in Materials Today: Proceedings, Elsevier Ltd: 4290-4298, 2018.

[16] O. Hegazy, J. Van Mierlo, P. Lataire, "Analysis, Modeling, and Implementation of a Multidevice Interleaved DC / DC Converter for Fuel Cell Hybrid Electric Vehicles," 27(11), 4445-4458, 2012.

[17] H. Al-Baidhani et al., "Sliding-Mode Voltage Control of Dynamic Power Supply for CCM," 2019 IEEE International Symposium on Circuits and Systems (ISCAS), Sapporo, Japan, 2019.

[18] Y. Wu, Y. Huangfu, R. Ma, A. Ravey, D. Chrenko, “A strong robust DC-DC converter of all-digital high-order sliding mode control for fuel cell power applications," Journal of Power Sources, 413, 222-232, 2019.

[19] Wang, J., Li, S., Yang, J., Wu, B., \& Li, Q. (2015). "Extended state observer-based sliding mode control for PWM-based DC-DC buck power converter systems with mismatched disturbances." IET Control Theory \& Applications, 9(4), 579-586.

[20] I. O. Lee. "A Hybrid PWM-Resonant DC-DC Converter for Electric Vehicle Battery Charger Applications." Journal of Power Electronics. 2015, 15 (5): 1158-1167.

[21] D. Boroyevich, H. Vanlandingham, W.T. Baumann, "Nonlinear Analysis and Control of Standalone, Parallel DC-DC, and Parallel Multi-Phase PWM Converters," 2001.

[22] J. Mahdavi, M. R. Nasiri, A. Agah, and A. Emadi, "Application of neural networks and state-space averaging to a DC/DC PWM converter in sliding-mode operation," IEEE/ASME Trans. Mechatron., vol. 10, no. 1, pp. 60-67, Feb. 2005.

[23] S. C. Tan, Y. M. Lai, M. K. H. Cheung, and C. K. Tse, "On the prac- tical design of a sliding-mode voltage controlled buck converter," IEEE Trans. Power Electron., vol. 20, no. 2, pp. 425 437, Mar. 2005

[24] S. C. Tan, Y. M. Lai, C. K. Tse, and M. K. H. Cheung, "A fixedfrequency pulsewidth-modulation-based quasi-sliding-mode controller for buck converters," IEEE Trans. Power Electron., vol. 20, no. 6, pp. 1379-1392, Nov. 2005.

[25] Riba, Jordi-Roger \& Moreno-Eguilaz, Juan \& Bogarra, Santiago \& Garcia Espinosa, Antonio. "Parameter Identification of DC-DC Converters under Steady-State and Transient Conditions Based on White-Box Models". Electronics. 7. 393. 2018 